\title{
When Students Can Choose: Online Self-Study or In-College Learning of English for Academic Purposes
}

\author{
Devora Hellerstein ${ }^{1}$, Tina Waldman ${ }^{2}$, Hanne Juel Solomon ${ }^{2}$, \& Michal Arnon ${ }^{1}$ \\ ${ }^{1}$ The Academic College at Wingate, Israel \\ ${ }^{2}$ The Kibbutzim College of Education, Technology and Arts, Israel \\ Correspondence: Devora Hellerstein, The Academic College at Wingate, Israel.
}

Received: June 9, 2020

doi:10.5430/wjel.v10n2p25
Accepted: July 6, 2020 Online Published: July 22, 2020

URL: https://doi.org/10.5430/wjel.v10n2p25

\begin{abstract}
This study aimed to better understand what motivations drive students to select a self-study massive open online course (MOOC) or an in-college course with an instructor. The students were enrolled in one of three level courses of English for Academic Purposes (EAP), which was an accredited course required for the completion of their Bachelor's Degree, at three teacher education colleges in Israel. The study applied a mainly quantitative data collection method, with a qualitative component. The researchers distributed a survey to 236 students studying in one of the two conditions. They compared survey results between the two groups to examine student background, motivations, and perceptions in relation to choice of preferred learning style. Findings indicated that demographic factors had little effect on the students' choice. In terms of student motivations, while some differences were found between the two groups in learning preferences, the greatest motivations for selecting a MOOC were extrinsic, with more students driven by financial and time constraints rather than a preference for autonomous learning. The perceptions of students who chose a MOOC indicated low learner readiness to study independently and, as such, a higher risk of not passing the required course. Despite claims that MOOCs represent the democratization of education - providing access to all, regardless of age, gender, financial resources, or other barriers, our findings reveal inequality between students learning English for Academic Purposes in higher education based primarily on financial resources.
\end{abstract}

Keywords: online learning, MOOCs, self-study, English for academic purposes (EAP), higher education

\section{Introduction}

\subsection{English for Academic Purposes}

English for Academic Purposes (EAP) refers to English for the purpose of learning in an English-speaking environment, reading academic texts, and conducting research and teaching in global frameworks (Flowerdew \& Peacock, 2001). It is essential for students for whom English is a foreign language in order to learn in academic institutions in English speaking countries. Moreover, as English is the international language used in research, students in countries where English is not the first language need to acquire Academic English in order to access academic and research materials.

With the era of globalization, teaching EAP faces multiple challenges. While traditionally students may have been considered well served just by being taught informational texts and reading comprehension skills, today's students need a much more extensive set of tools for coping with the requirements of a dynamic, globalized academic world and job market. In order to participate in intercultural citizenship and the academic community, they must understand and produce spoken and written English in a wide variety of both formal and informal situations and contexts (Kelly, 2013). This, among other issues, makes learning EAP a necessary and complex process, involving the learning of all four language skills: reading, writing, speaking, and listening. Imposed by globalization processes, alongside the changes that EAP has undergone, technological educational solutions have been developed with the aim of offering access to knowledge, education, and language learning to a wide global community (Prensky, 2012). 


\subsection{The Debate on MOOCs}

\subsubsection{Types of Online Learning}

While distance learning dates back to the 1890s when universities permitted students to learn outside of their physical campuses, only a century later did technology enable the first entirely online course to be offered in 1981 (Wallace, 2003). Online courses have become increasingly available since then. The effects of online distance learning on education, for good and for bad, have been the subject of much recent debate (i.e., Corbeil, Khan, \& Corbein, 2019; De Corte, Engwall, \& Teichler, 2016; Gameel \& Wilkins, 2019; Guri-Rosenblit, 2006; Wang, Hall, \& Wang, 2019).

There are several types of distance learning which require clarification before their effects can be discussed. The most widely used format is the hybrid or blended course, which refers to face-to-face instruction with an online component, mainly for student practice and for submitting assignments, in addition to promoting interaction between students and their teacher and among peers outside of class (Yao, 2019). Another format of the online course is entirely online, with no physical contact with other participants in the course, but with the teacher serving as an online mediator or facilitator of the course in terms of comprehension of the materials and promoting discussion among the students (Kebritchi, Lipschuetz, \& Santiague, 2017).

Another form of online learning is through the Massive Open Online Course (MOOC), which refers to a platform capable of serving an unlimited number of students. Several forms of MOOCs have been developed since the first MOOC was made available. Cole and Timmerman (2015) describe two types of MOOCs. C-MOOCs refer to courses with interaction among the students, who act as peer-tutors and conduct discourse about the course contents and structure. X-MOOCs refer to courses which offer automated instruction for students' self-study without student or teacher interaction. L-MOOCs refer to language MOOCs, which offer diverse forms of online language learning.

\subsubsection{Proposed Benefits of MOOCs}

Advocates of MOOCs claim that this method of learning can provide equal access to any individual who desires to learn, regardless of social class, previous education experience, or any other potential constraint. According to MOOC proponents, second-chance and part-time students seeking more flexible and independent learning, now have an opportunity to study in courses to which they were previously denied access. For instance, according to Alcorn, Christensen, and Kapur (2015) MOOCs provide higher quality education than that available to those graduates in India and the Global South seeking to bridge the gap between the education they received and the demands of their profession. Others have noted the opportunities MOOCs afford to certain groups denied access to education, such as female students in certain regions who cannot attend traditional college campuses (Al Megren \& Yassin, 2013). MOOCs also offer knowledge to lifelong learners who are either professionals attempting to stay updated in their profession or those wishing to gain information in an array of subjects for their own interest (Corbeil et al., 2018). As Hew and Cheung (2014) noted in their review, "...some believe that MOOCs represent the ultimate democratization of education, by making education more accessible to as many people as possible" (p. 46).

A review on motivations for enrolling in MOOCs by Hew and Cheung (2014) identified four main reasons: 1) an interest in learning a new subject or to widen one's existing knowledge; 2) curiosity about MOOCs and a desire to try out this new learning experience; 3) personal challenge; and 4) professional certification. The fact that MOOCs are predominantly free of charge was considered an added incentive to enroll in them. These motivations are in line with the claims made by proponents of MOOCs arguing for the equal education opportunities and access they provide to diverse populations of students, lifelong learners, and professionals.

\subsubsection{Proposed Limitations of MOOCs}

Despite the apparent benefits that MOOCs are supposed to offer, low student completion rates indicate that MOOCs have failed to deliver on their promise. While there is much debate surrounding MOOCs, there is general agreement that high dropout rates have been the Achilles heel of these courses ever since their inception. The Online Course Report (2016), which studied MOOCs and student registration globally, reported a 5\% retention rate for all students who enrolled in all MOOCs around the world. This means that $95 \%$ of students who enrolled in such courses did not complete the course. In fact, they often did not view beyond the first or second session. These rates have remained more or less the same to date, with most studies reporting between 5-10\% completion rates (e.g., Fioriksdottir, 2018; Wang et al., 2019).

The literature has examined different types of MOOCs, diverse learners registered to MOOCs, and the role of teachers or facilitators, among other issues, in an attempt to better understand the high dropout rate. Hew and Cheung's review (2014) identified four main challenges to MOOCs: 1) lack of incentive; 2) lack of background knowledge for understanding the contents, with no one to turn to for help; 3) unclear assignments; and 4) lack of Published by Sciedu Press 
time to commit to completing the course.

The vast majority of the literature supports and strengthens the finding that with no support and no one to turn to for help, the majority of students are not likely to complete a MOOC. Research has repeatedly concluded that without meaningful interaction with a teacher mediating or facilitating materials and knowledge, and without interaction among peers, the student satisfaction rate is low, as is completion of the course (e.g., Cole \& Timmerman, 2015; Guri-Rosenblit, 2006; Garrison \& Cleveland-Innes, 2005; Hew \& Cheung, 2014; Wallace, 2003). A study comparing the same language courses at different levels in three modalities - blended, distance (including online interaction with a tutor), or open self-directed (non-tutorial) - found the lowest completion rates among the open self-directed modality (Frioriksdottir, 2018). The evidence seems to overwhelmingly support the notion that student support from either a teacher/facilitator or peers, and their interaction, are essential for learning.

As a way to promote autonomous learning and increase completion rates, MOOCs began to be offered to college students for accreditation. It was assumed that college credit would serve as a positive incentive for students to complete courses and to counter the high dropout rates. Yet, Wang et al. (2019), who examined accredited MOOCs in China over a three-year period, found that overall students were dissatisfied with their MOOC learning experience. In the institution where the study was conducted, students were obligated to take four online accredited courses. While some students reported satisfaction with the flexibility in learning and ownership in learning, more than half were dissatisfied, reporting a low quality of the courses, technical problems, and mainly the unengaging mode of learning with its lack of interaction. Widespread absenteeism, or leaving the video on without watching, was reported, and many students skipped the entire MOOC, paying others to replace them. Wang et al. concluded that "merely relying on students' self-regulation to engage in the courses, without even guiding students to improve their self-regulation would be unrealistic" (p. 9). Another study of accredited MOOCs was conducted in Japan, which found that contrary to the expectation that young Japanese college students would have ICT learner readiness for MOOCs, the majority possessed ICT for daily use but did not have the digital skills needed for educational purposes (Mehran, Alizadeh, Koguchi, \& Tekmura, 2017). In this study as well, students preferred face-to-face instruction over online learning.

\subsubsection{The Significance of Learner Readiness}

Learner readiness has been the focus of recent literature on MOOCs. Learner readiness includes, inter alia, the background knowledge necessary to understand the contents of a course, the emotional and psychological abilities to study autonomously, and the digital skills to navigate within an online environment. While proponents of MOOCs have argued for access to education they provide to all learners, the profile of the majority of students enrolled in MOOCs has been highly educated students - either postgraduates or, to a lesser extent, first and second degree students (see Alcorn et al., 2015; Gameel \& Wilkins, 2019; Liyanagunawardena, 2015). It would seem that students with a higher education possess the greatest learner readiness in comparison to students without this advantage, raising questions regarding whether MOOCs are in fact accessible to all learners.

In their study of learner readiness, Gameel and Wilkins (2019) compared ICT skills, self-efficacy, and locus of control between students enrolled in MOOCs in North America, Europe, Latin America, and the Caribbean, and the Arab States. Their findings indicated that while the majority of the students all had similar access to the Internet and technological tools and were enrolled in one of the same five MOOCs (some of them delivered in English and others in Arabic), cultural differences emerged regarding learner readiness. Students in the Arab States had the lowest level of engagement with ICT and the lowest level of locus of control, in comparison to Europeans and North Americans. Moreover, in support of the abovementioned findings on student profiles, students with professional, Master's or Doctoral degrees had the highest level of learner self-efficacy and locus of control. Students with the highest ICT engagement had at least some college background, and male students had higher ICT engagement and learner self-efficacy than female students.

Based on the continuing debate and existing findings on MOOCs, the current study examined student motivations for electing either a free MOOC course or a paid face-to-face course in EAP, which is required for a Bachelor's Degree in Israel. Unlike previous studies, students in the current study could opt for the modality of study for a requisite course.

\subsection{Context of the Study}

As in much of the world, students at institutions of higher education in Israel are required by the Council for Higher Education (CHE) to reach an exemption level in English in order to receive their Bachelor's Degree, so that they can cope with their academic requirements in their field of study. Students are placed according to a national exam into 
one of four levels, and are required to take between one to four English courses until reaching the exemption level, unless placing at an exemption level to begin with.

In 2015, a reform in EAP studies by the CHE enabled students to choose whether to take their English courses on campus, or to enroll in MOOCs and study independently at no cost. The availability of these online courses has impacted EAP studies in general, with implications for the future of the field, its practitioners, and most importantly, its students. Initial reports indicate that some $60 \%-75 \%$ of the students who opted to study with MOOCs failed the post-course exams, which is the sole assessment parameter. This change is especially worrying, seeing that the level of English needed for academic studies is one of the major barriers for many students, especially from certain sectors in Israeli society, who want to advance their education (Feniger \& Ayalon, 2015).

\subsection{Research Questions and Hypotheses}

This study aims to provide a better understanding of the motivations driving EAP students to opt for a self-study MOOC or an in-college course with an instructor. The following research questions guided this study:

1. Which language and demographic background factors, if any, affect students' choice?

2. Which motivations affected students' choice?

3. Do students' self-perceptions about learning in general and learning in English affect their choice, and if yes, in what way?

We anticipated that students would select a course based on their preferred form of learning and their learner readiness. Students who perceived that they lacked learner readiness in general, and in English in particular, would prefer the interaction and support of an instructor and peers. Moreover, they would choose an established framework with a set schedule. These factors would underlie their choice for a face-to-face course. Students who opted for the MOOC would be students with the perception that they possessed learner readiness. The main factor underlying their choice for a MOOC would be to attain independent, autonomous, and flexible learning. Additional factors could be the convenience of studying at home, the ability to fit in studies within their work schedule, and the low cost. Furthermore, students who suffer from feelings of anxiety about studying English, or attribute little importance to the subject, may choose the MOOC in order to avoid studying with a teacher and peers in a classroom.

\section{Methods}

\subsection{Participants and EAP Courses}

A total of 236 students from three teacher education colleges, representing the general student population in Israeli society and the diversity of its sectors, participated in the study. The average age of the students was 24 years. Of the respondents, $18 \%$ were male and $82 \%$ were female, a gender distribution that is representative of the teaching body in Israel (Knesset, 2019). In terms of choice of course, 18.8\% chose a self-study online English course (46 students) and are referred to as "online students" in the current study, while $80.2 \%$ (190) chose a teacher-supported in-college English course, and are referred to as "in-college students" in the current study.

The colleges where the students were enrolled are supervised by the CHE and offer a 4-year B.Ed. program. The courses given by the EAP units in the colleges are either face-to-face or blended learning instruction. The instruction includes frontal teaching and group work, with instructors focusing on the four skills of reading, writing, speaking, and listening, with an emphasis on reading comprehension. The students are required to complete individual and collaborative assignments and presentation tasks, as well as to take a midterm and final exam.

In all blended instruction courses, the majority of learning hours are face-to-face with an instructor, supplemented by online instruction on the MOODLE (Modular Object-Oriented Dynamic Learning Environment) platform. Online instruction consists of asynchronous tasks, including vocabulary and grammar exercises, reading practices, and discussion forums in which students and the teacher take part. The final grade for the college courses is composed of both coursework and the final exam grade, which according to the CHE regulations, must be above 60 in order to pass the course.

The MOOCs provide self-study of the same three lower levels of EAP as offered on campus, with the fourth and highest level required to be taken on campus at no additional cost. The MOOCs at each level are identically structured, comprising several units of information. These include a target article and recorded mini lectures which alternate between English and Hebrew, describing reading strategies such as predicting, context clues, determining text purpose, and structure, etc. Each unit ends with a practice multiple choice quiz which is graded automatically (retrieved from http://study.onl.co.il/). Students who opt for a MOOC must pass a national post-exam in order to advance to the next level. 
Some 400-600 students were enrolled in EAP courses in each college at the time of the study. Students learning EAP in the three lower academic levels in each of the colleges were recruited to take part in the study.

\subsection{Tools}

This study was mainly quantitative, with a qualitative component, and based on data collected from a survey constructed for the purpose of the study. The Survey for Students Enrolled in EAP Courses (SSEEAP) comprises five sections. Section A includes 10 demographic background questions. Section B includes four questions regarding their EAP background; students indicated their choice of course (MOOC or face-to-face), the level they were studying (Pre-Basic, Basic, Advanced A, or Advanced B), how many previous levels they had taken at the college before reaching the current level, and their score in the national English placement exam. Section $C$ is an open-ended question asking students to provide the three foremost reasons behind their choice to study independently online or in a face-to-face college course. Section D also targets information about students' motivations for their choice of course type; students respond by choosing their position between two opposite statements on a scale. For example, between the statements "I study better without a group of other students" (1) and "'I study better with a group of other students" (4), students mark their position on a scale of 1-4. Similarly, students are asked to indicate their position on a scale from 1-4 regarding the statements "I can study independently and have no need for a teacher" (1) and "I need a teacher in order to learn" (4). Statements in this section relate to students' learning preferences, including intrinsic and extrinsic motivations, their past experiences in learning English, and the importance they attribute to learning English. Section E is composed of statements of self-perception about learning English, with which students are asked to rate their level of agreement on a 5-point Likert scale adapted from Daly and Miller (1975). Part F includes one open-ended question asking students if they have any additional comments. The survey was sent to students in Hebrew and Arabic. Each student chose to fill out the survey in their language of preference, and their open-ended answers were translated to English.

\subsection{Procedure}

Following a pilot, the SSEEAP was designed for all students to enable comparison between the two groups. Reliability of the survey was conducted by a Factor Analysis and an Alpha Cronbach test. In the 2016-17 academic year, the SSEEAP was distributed to all students in the three colleges registered for EAP courses. The SSEEAP was distributed online in a Google survey format which the students received by email.

\subsection{Data Analysis}

Statistical analysis was conducted using the SPSS Statistics 23.0 program. Differences in demographic and background variables between students learning in online courses and students learning in college courses was conducted by means of $\mathrm{Chi}^{2}$ tests for the categorical variables, and ANOVA tests were conducted for the quantitative variables. Statistical significance was set at $\mathrm{P}<0.05$ for all the tests.

The open questions were independently examined by two of the researchers, both explicitly and holistically, while paying attention to the themes that emerged (Ryan \& Bernard, 2000). Answers were coded and thematically categorized (Dey, 1993).

\subsection{Ethical Considerations}

Student participation was voluntary. Students received a written explanation of the purpose of the study, its expected benefits, the policy of confidentiality that the researchers were required to adhere to, and the students' right to take part or decline participation. Students who agreed to partake in the study opted in by answering the online survey they received. Ethical approval was granted by each of the institutions where the research was conducted.

\section{Results}

\subsection{Registration Data}

Of the 236 students who participated in the study, 190 (80.2\%) registered for in-college courses and 46 (18.8\%) registered for online courses. The course levels in which the students were enrolled can be found in Table 1: 
Table 1. Distribution of student enrollment according to course level and course type

\begin{tabular}{llllll}
\hline Level & $\begin{array}{l}\text { In-College } \\
\text { Course } \\
(\mathrm{N})\end{array}$ & $\begin{array}{l}\text { In-College } \\
\text { Course } \\
(\%)\end{array}$ & $\begin{array}{l}\text { Online } \\
\text { Course } \\
(\mathrm{N})\end{array}$ & $\begin{array}{l}\text { Online } \\
\text { Course } \\
(\%)\end{array}$ & Total \\
\hline Pre-Basic & 68 & $35 \%$ & 13 & $28 \%$ & $81(34 \%)$ \\
\hline Basic & 28 & $14 \%$ & 21 & $46 \%$ & $49(21 \%)$ \\
\hline Advanced A & 94 & $49 \%$ & 12 & $26 \%$ & $106(44 \%)$ \\
\hline
\end{tabular}

\subsection{Demographic Data}

No statistically significant differences between in-college and online students were found in terms of mean age (in-college $\mathrm{M}=23.8, \mathrm{SD}=3.73$; online $\mathrm{M}=24.02, \mathrm{SD}=2.38$ ), $t(227)=0.33 p<0.05$. Similarly, no statistically significant differences were found in gender distribution, with $83.5 \%$ female and $16.5 \%$ male students comprising the in-college student group and $73.3 \%$ female and $26.7 \%$ male students comprising the online student group, $\chi^{2}(1)=2.61 p>0.05$.

In terms of native language distribution, statistically significant differences were also not found. Among the online students, $85.8 \%$ were native Hebrew speakers, $6.7 \%$ were native Arabic speakers, $4.4 \%$ were native Russian speakers and $6.7 \%$ were native speakers of other languages (French and Polish). Among the in-college students, $82.2 \%$ were native Hebrew speakers, $8.42 \%$ were native Arabic speakers, $2.1 \%$ were native Russian speakers, and $3.7 \%$ were speakers of other languages (French, Portuguese, Spanish, Amharic, and Persian), $\chi^{2}(3)=2.36 p>0.05$.

When asked about learning disabilities, no statistically significant differences were reported by students who chose in-college courses (40\%) in comparison to students who chose online courses (40\%), $\chi^{2}(1)=0.65 p>0.05$.

\subsection{Motivations for Choice of Course}

To better understand the reasons that motivated students to choose course type, students rated 12 reasons on a scale of 1-4 ('1' indicating reasons more plausible for choosing an online course and '4' the opposite position indicating a reason more plausible for choosing an in-college course). In order to get a clearer view of motivations, answers '1-2' were collapsed to ' 1 ' and answers '3-4' were collapsed to '2'.

Our findings indicated statistically significant differences between the two groups of students for 11 out of the 12 reasons provided in the questionnaire (see Figure 1). Interestingly, in all items a much higher percentage of agreement than anticipated was found, with reasons more plausible for registering to in-college courses among the students who registered for online courses. Most striking was the high percentage of agreement among students registered for the online course with the statements I study better under the guidance of a teacher" (65.2\%), "I prefer to ask questions and receive answers from a teacher" (54.3\%), and "I study better with a group of other students" (52.2\%). Surprisingly, almost half agreed with the statements "Homework, quizzes, and a midterm exam prepare me for the final exam" (48.8\%) and "grades in the other tasks help raise my final grade" $(46.3 \%)$. Moreover, almost a third of the online students answered that they had a need to study with a teacher in a classroom (32.6\%), and needed the support and encouragement of a teacher (30.4\%). 


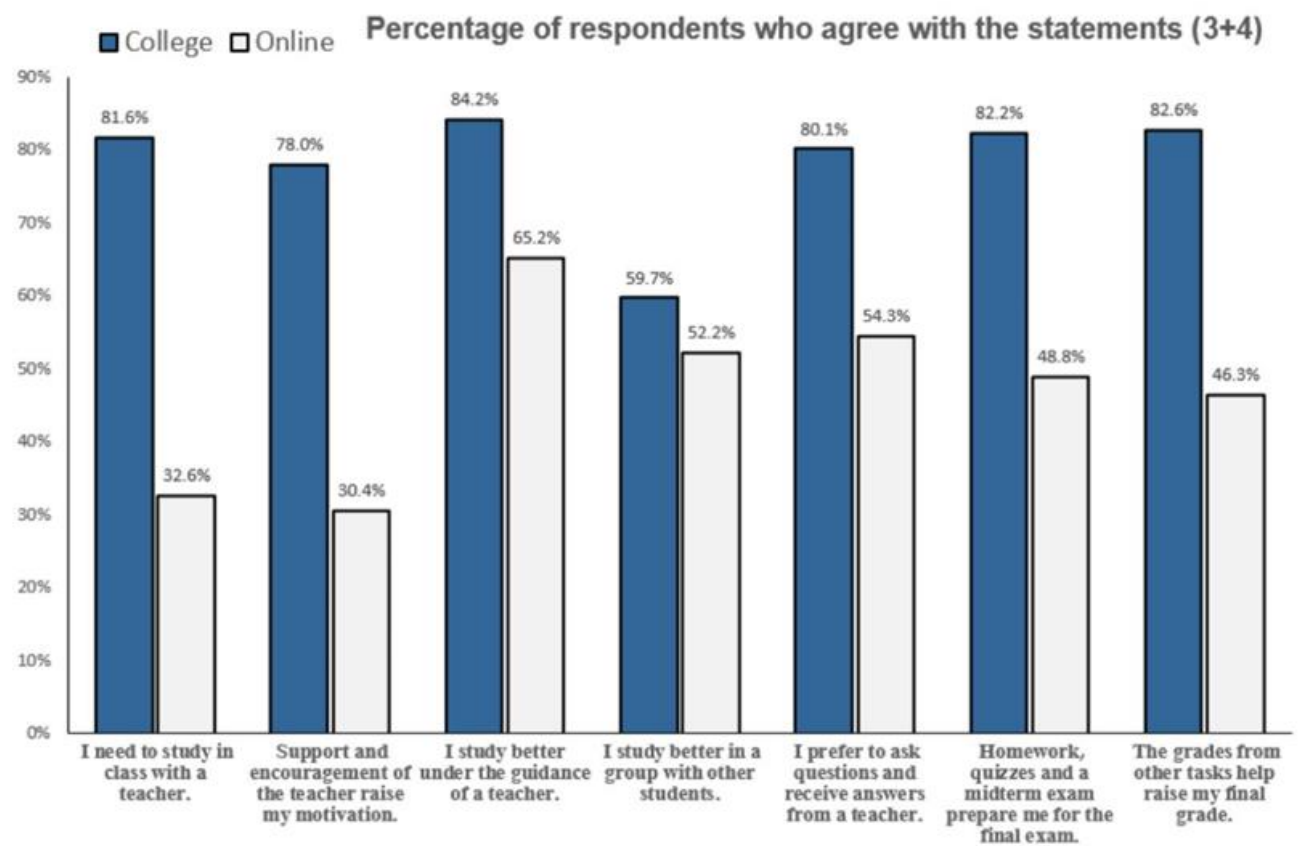

Figure 1. Percentage of respondents who agree with the statements (plausible reasons for choosing an in-college English course)

In terms of practical reasons motivating the choice of course, significant differences between the two groups also emerge. The highest agreement with reasons for choosing an online course was "financial savings" $(84.4 \%)$ and "work does not enable me to study English at the college" (86\%). Nevertheless, a surprising $32.6 \%$ of these students also agreed that they have "a preference to study within a framework with a set schedule".

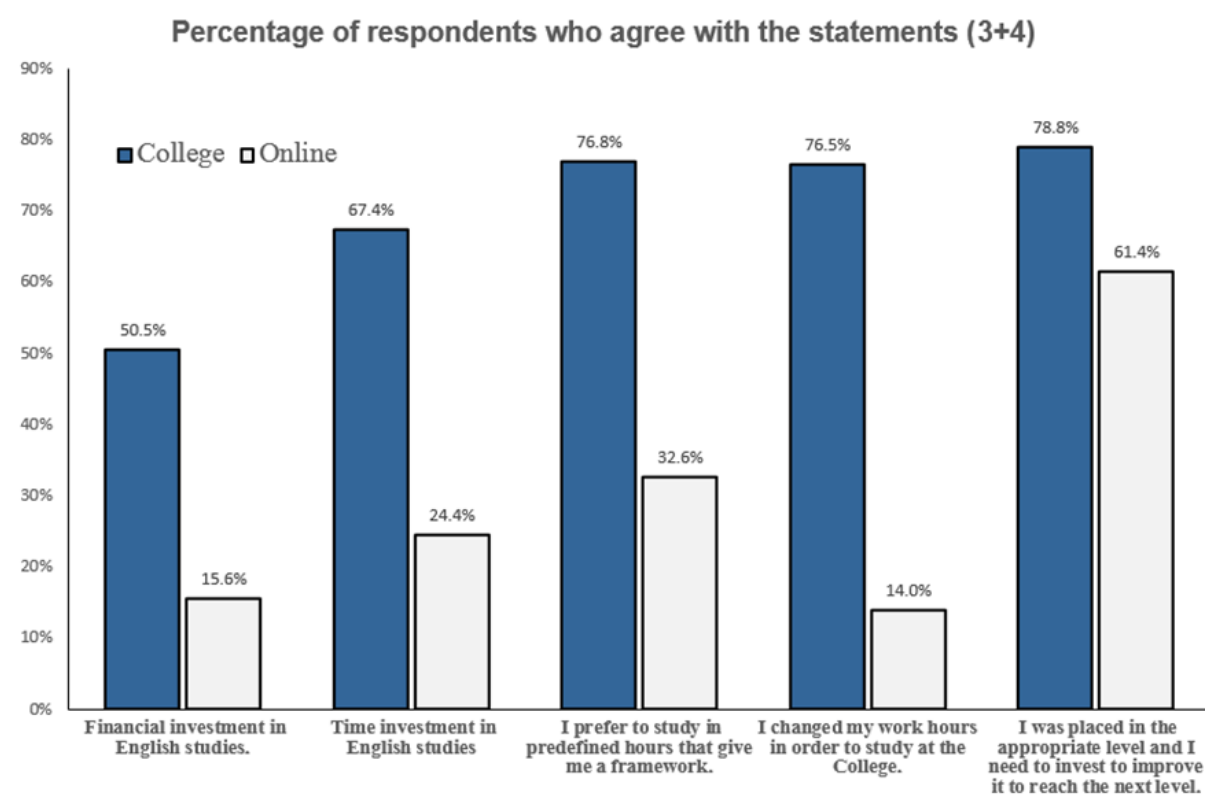

Figure 2. Percentage of respondents who agree with the statements (plausible practical reasons for choosing an in-college English course) 


\subsection{Self-Perceptions about Learning}

To better understand student perceptions and background in self-study and English language learning, students had to choose the option that best describes their attitude regarding 11 statements about their learning, on a 5-point Likert scale (" 1 " referring to most negative perception and " 5 " most positive perception). To get a clearer understanding of their views, scores " $1-2$ " were collapsed to " 1 ", neutral standing was attributed " 2 ", and "4-5" were collapsed to " 3 ".

$\mathrm{A} \mathrm{Chi}^{2}$ test revealed a significant difference between the groups in perception of self-study $\left(\chi^{2}(2)=12.93 p>0.05\right)$. (see Figure 3). As expected, more online students (60\%) in comparison to in-college students $(33.2 \%)$ perceived their ability to study independently as good-excellent. At the same time, surprisingly, almost $40 \%$ of the students who chose to study online did not rate their independent study ability as good-excellent.

\section{Percentage of respondents who agree (4-5) with the statements regarding English studies.}

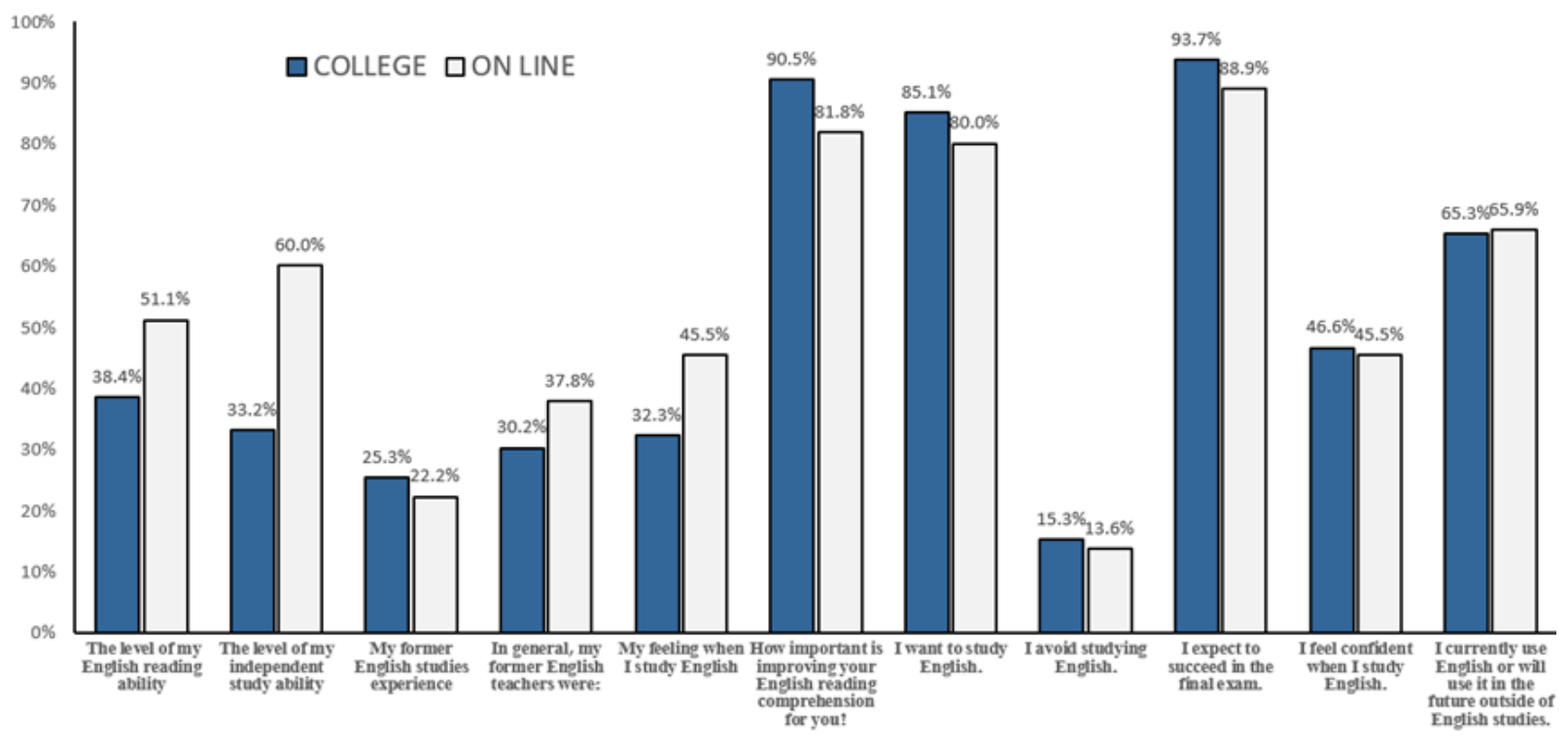

Figure 3. Percentage of respondents who agree with the statements regarding their English studies

No statistically significant differences were found on any of the other items. Particularly interesting findings, however, revealed that the students in both groups had a strong desire to learn English and improve their English reading comprehension, and that they perceived knowledge of English as an essential skill. The vast majority agreed with the statement "I want to study English" (85.1\% of in-college students and $80.1 \%$ of online students), and the majority in both groups almost equally disagreed with the statement "I avoid learning English" $(15.3 \%$ of in-college students and $13.6 \%$ of online students). Figure 4 provides a distribution of scores regarding student perceptions of their study needs and preferences, and Figure 5 presents a distribution of scores of student perceptions regarding investment and preferences in their English studies. 


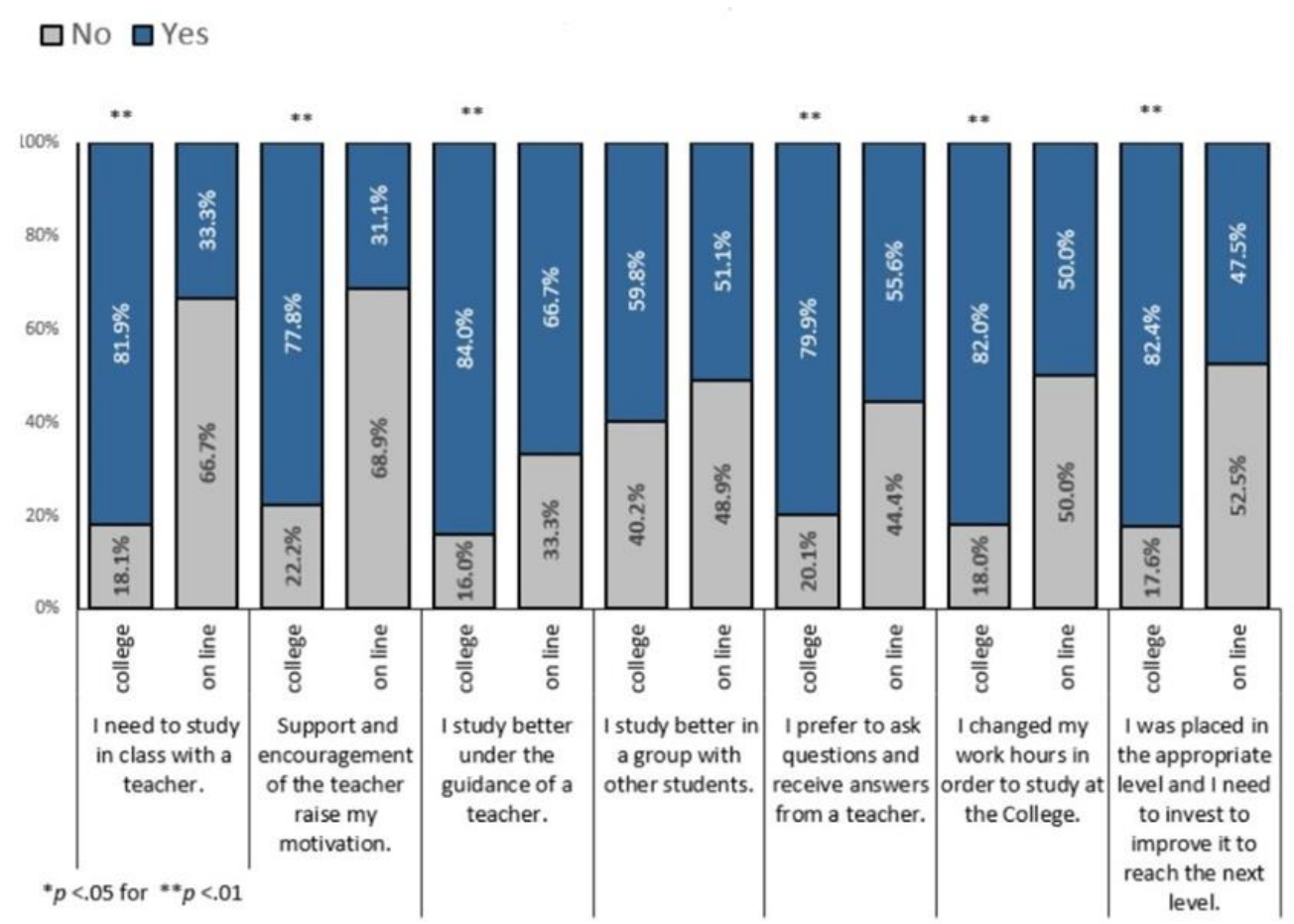

Figure 4. Distribution of scores regarding student perceptions of their study needs and preferences

$\square$ No $\square$ Yes

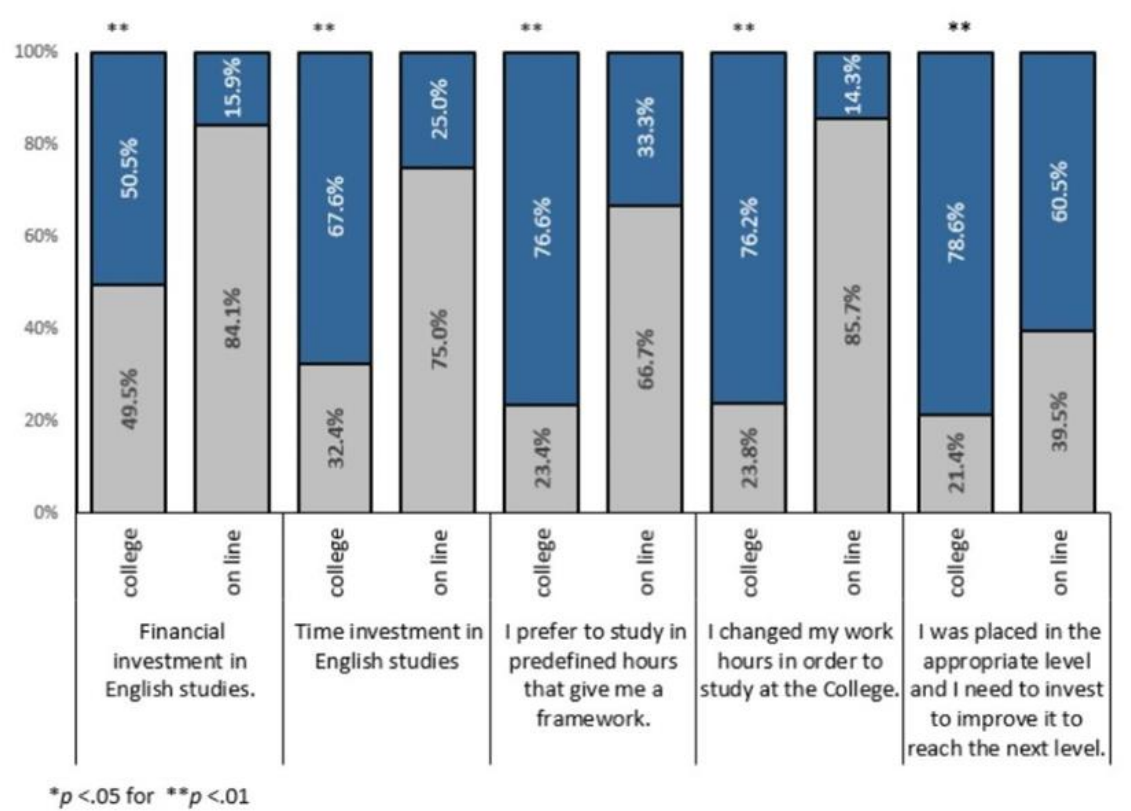

Figure 5. Distribution of scores of student perceptions regarding investment and preferences in their English studies

\subsection{Open-Ended Question: Reasons for Choice of Course}

When analyzing the open-ended questions about student motivations for choosing course type, several themes emerged. These included a desire for a teacher, scheduling reasons, financial reasons, perceived ability to study 
independently, and perceived ability in English. As expected, most of the students taking an in-college course gave preference to 'studying under the guidance of a teacher' as their main reason for choosing a college course. Students mentioned teacher support, studying in an organized manner, assistance and personal guidance, someone to turn to, and studying in a classroom with a teacher as reasons for their choice of an in-college course.

I have chosen to study with the guidance of a teacher because I wanted the support of a professional.

I need someone who can guide me so that I can improve my English in the best way and study effectively.

In addition, the in-college students reported that they preferred a clear framework, as they believed that this enabled them to succeed in their studies. Sitting and studying in a classroom at a specific time with other students was viewed as essential for their learning. They expressed a lack of self-discipline for studying independently, and feared that their level of English was not high enough for self-study.

Because I distrust my independent learning, I chose a college course under the guidance of a teacher rather than an online course.

My English level is so low that I cannot study independently.

In contrast, the online students said that they chose independent study for convenience as opposed to the inconvenient scheduling of college courses, such as attending college an extra day or late in the evening. Many students reported that the course schedules at their college were at inconvenient times, and at times when they preferred to work. However, many indicated that they would have rather studied in a college course had the schedule suited them.

... the courses at the college are at a time that I have to work, I wish the courses were in the morning hours.

... I have to work. The teachers are fantastic and it is definitely better to study at the college, but unfortunately it is at the time that I have to work.

For online students, a major motivation cited for choosing independent study was an economic one; they wished to avoid the additional cost of a college course. Some added that if it hadn't been for the high expense of college courses, they would have chosen them over the online courses.

I chose the online course because the price of a college course is very high for me - this was a financial consideration

Finance and time - these are only reasons. Otherwise, I would have preferred a college course.

In terms of English level and ability to study independently, several online students perceived themselves as capable, although the responses such as the ones below appeared much less frequently.

I can do what is done in class on my own.

I can advance at my own pace, I am not dependent on others...freedom, independence.

In summary, the answers to the open-ended questions provided by both in-college and online students reveal a pattern similar to the answers of the closed survey questions. The motivations provided by students for their choices further sharpen the view that the main forces driving students to choose online courses as opposed to in-college courses are issues of convenience and cost, significantly outweighing the preference for independent study. In contrast, the main reason for choosing to study in a college course on campus is the desire for a personal teacher for support.

\section{Discussion and Conclusions}

\subsection{Student Motivations for Choosing either MOOCs or In-College Courses}

This study aimed to better clarify what motivations drive students to select EAP self-study online or in-college courses with an instructor. For this purpose, the first question we examined was whether demographic differences were associated with the choice of course type. Results indicated that students who opted for self-study online learning and those who opted for in-college learning had very similar compositions. As such, it does not appear that age, gender, cultural background, or native language significantly affected student choices. A small but statistically insignificant difference was found in terms of gender, indicating that perhaps a higher number of male students prefer to study independently online. In addition, a small, statistically insignificant difference in native language was found, indicating that perhaps more speakers of Hebrew as a second or third language prefer to study independently online. This may be because the main language of instruction in all three colleges examined is Hebrew, and although the courses are in English studies, explanations sometimes take place in Hebrew, especially at the lower levels. 
Explanations in the online program are also in Hebrew, however students have the choice of whether to listen to or disregard them.

When looking into the student motivations for choosing the type of course, as anticipated, differences were found between the two groups regarding study preferences. However, the findings indicate that an alarmingly large number of students who selected a MOOC stated they would have preferred to study in an in-college course, with $65 \%$ agreeing that they would study better under the guidance of a teacher and over half agreeing that they would prefer to communicate with a teacher and would benefit from studying in a group with other students. This finding was supported by the students' qualitative answers.

As hypothesized, the main motivations driving students to choose an online course were financial savings, time saving, and convenience. These findings were also highly supported by the students' qualitative answers. Moreover, many students expressed a need for scheduling college courses at more convenient times, which would enable them to fit work within their study schedule. In the three institutions examined, as is the case in most teacher education colleges, English courses are provided as external studies to the core college schedule. As such, English lessons take place in the late afternoon or evening hours, or on a day that the students would otherwise have off. That is, these are the hours that most students have available for work in order to finance themselves and their studies.

While the researchers' assumptions regarding student choice of course type for financial and time-saving reasons were supported by the findings, the hypothesis that students prefer autonomous learning was not highly supported, with about two thirds of the online students expressing a preference to study under the guidance of a teacher and about half preferring to study with peers. The hypothesis that one of the motivations for choosing a MOOC is the avoidance of studying English in class due to anxiety, or the perception that it is an unimportant subject, was refuted by the data. English level was self-rated as only slightly higher by online students, and both groups equally perceived their English studies as important. Also, a high percentage in both groups expressed a desire to study and improve their English. Thus, very little difference between the two groups could be discerned in terms of their perceptions or attitudes towards learning English. The only significant difference between the two groups was unrelated to English per se, with about twice as many MOOC students perceiving that they have a high ability to study independently in comparison to in-college students. Nevertheless, as $40 \%$ of the students who opted for self-study did not perceive their independent study abilities as good, these findings are worrisome.

The above findings indicate that student motivations for choosing a self-study online course in English is for the most part driven by extrinsic factors of cost and convenience. In contrast, internal motivations, such as a preference for autonomous learning, a preference to study without the distractions of other students, or not to be constrained by course assignments, were not prevalent.

\subsection{Lack of Learner Readiness Predicts Lack of Success on MOOCs}

These findings support claims in the literature that learners, especially those who do not yet hold a degree, require the guidance and support of a teacher (e.g., Christensen et al., 2013; Gameel \& Wilkins, 2019; Guri-Rosenblit, 2006; Hew \& Cheung, 2014; Mehran et al., 2017; Wallace, 2003; Wang et al., 2019). In the current study, the students indicated that they were well aware of this need, and the majority clearly expressed a preference to study in a class under the instruction of a teacher. The study indicates that in general students have no illusions about their self-study abilities and learner readiness, but nevertheless opt for MOOC learning, driven by other motivations. As such, the findings also support findings in the literature that students opt for MOOCs not as a preferred choice of learning, but rather due to financial, professional, or family constraints (Corbeil et al., 2018; Gameel \& Wilkins, 2019; Guri-Rosenblit, 2005).

The study findings also support the argument that learner readiness is essential to MOOC learning (see Alcorn et al., 2015; Gameel \& Wilkins, 2019; Hew \& Cheung, 2014). While we do not have data regarding student engagement in the MOOCs, the majority of online students reported quite a low level of learner readiness, as expressed by their reported need for the guidance of a teacher, peers, and a set schedule. Based on Wang et al. (2019) and the large body of data indicating low completion rates, it can be assumed that many of the students did not in fact watch and follow all the units, if any. In addition, as $65 \%$ of the students were enrolled in the two pre-academic levels, it can also be assumed that they lacked the basic language skills needed to be able to follow and complete the MOOC tasks (Hew \& Cheung, 2014). The findings of the current study indicate that even when the course is accredited and required for completion of their degree, when lacking learner readiness students will not successfully complete the course.

\subsection{Claims of Equal Access to Education by MOOCs Challenged}

While supporters of MOOCs have argued that such a format provides equal access to any individual who desires to 
learn, regardless of social class, previous education experience, or any other potential constraint, in the context of the current study the opposite result has in fact been found. The stated reason for the decision by the CHE to offer free online English courses to students of higher education was to ease the financial burden of additional tuition fees, and thus make English studies more accessible to all students. However, the findings of the current inquiry indicate a gross inequality between students, based on financial resources. The students who opted for MOOCs have been predominantly driven by financial reasons and the convenience of allowing them time to work. Students with better financial means can enjoy the instruction, support, and encouragement of a teacher, the benefit of a study group, and teacher and peer feedback - many of the benefits that online students indicated they would have preferred. As many as $65 \%$ of the online students reported they studied better under the guidance of a teacher, and $52 \%$ reported they studied better with a group of other students. As such, in contrast to the suggestion that a MOOC format provides equal access to any individual who desires to learn, our study indicates otherwise. Our findings reveal that the inequality between students in EAP requisites in higher education are based primarily on financial resources.

We are unable to compare the MOOCs and the in-college courses, as so many variables differ (contents, teachers, student investment, exams), making any comparison invalid. As such, we cannot make claims regarding the greater effectiveness of one over the other. The only data available are that success rates are significantly higher among students of the in-college courses in the three colleges examined in the current study. During the time period examined, 8\% of students in the three colleges did not pass their English courses and were required to repeat them, while 59\% of students who opted for an online course were required to repeat the level. Regardless of the reasons behind the current difference in success rates, the negative consequences are clear.

\subsection{Implications and Limitations}

We believe that these findings raise questions regarding the repercussions of national or institutional initiatives offering MOOCs, particularly in EAP. Prior to the implementation of any such large scale initiatives, pilot trials and rigorous research should be conducted to examine students' learner readiness and self-study skills. Based on the results, student needs should be addressed and revisions carried out in order to raise the potential effectiveness of such initiatives.

The findings of the current study may assist institutions of higher education in taking into consideration student needs - particularly scheduling required courses at more convenient times, as well as in guiding students to make more informed choices to facilitate their academic success. Moreover, the findings of this study contribute to the scant body of knowledge that currently exists on MOOCs in the field of EAP learning, shedding light on student motivations and learner readiness.

There are several limitations to the study which must be taken into consideration. One limitation is the MOOC for which the students register. This program was approved by the CHE and is offered to all students learning in institutions of higher education in Israel. Notwithstanding, the program is not without its critics, and professionals in the field have raised concerns regarding its quality as a program for independent learning. In addition, there is no way to monitor whether students in fact study the program materials. However, the aim of the study was not to examine the quality of the online program, but rather why students choose to take it and what the outcome is in terms of success or failure in the final exam. A second limitation is the population of the students examined. The participants are a representative sample of students learning in teacher education colleges. This population is not necessarily representative of all students learning in institutions of higher education, as students learning in academic colleges and universities may have different characteristics. As such, the generalizability of the findings is limited to teacher education colleges. A third limitation is the survey method used in the study. The use of self-report has its limitations, such as social desirability or false answers. In addition, the sample of online students was smaller than that of the in-college students. Future research exploring student motivations and perceptions of MOOCs should be conducted on a larger scale, and qualitative interviews with students may provide a more complete view of the various aspects under consideration.

\section{Conclusions}

Despite the above limitations, some conclusions can be reached. When offering accredited MOOCs to undergraduate students, particularly in EAP, learner readiness and motivations for choosing them should first be established. Students should not be encouraged to take a MOOC unless they have advanced self-study skills, high motivation for autonomous learning, and possess learner readiness in terms of the fundamentals of understanding and following online lessons and digital skills. It can also be concluded that a better format for undergraduate students would be a MOOC supported by a teacher or facilitator, rather than stand-alone self-study courses. Most importantly, MOOCs should not be an option made more financially viable to students 
than another, and, if given a choice, MOOCs and in-college courses should be made equally accessible financially to students. Equality in education refers to ensuring that students are provided equally with the tools and support needed for true access to learning.

\section{Acknowledgements}

We wish to extend our gratitude to the MOFET Institute for Research, Curriculum and Program Development in Teacher Education for funding this study.

\section{References}

Alcorn, B., Christensen, G., \& Kapur, D. (2015). Higher education and MOOCs in India and the global south. Change: The Magazine of Higher Learning, 47(3), 42-49. https://doi.org/10.1080/00091383.2015.1040710

Al Megren, A., \& Yassin, S. Z. (2013). Learning object repositories in e-learning: Challenges for learners in Saudi Arabia. European Journal of Open, Distance and E-Learning, 16(1), 115-130.

Christensen, G., Steinmetz, A., Alcorn, B., Bennett, A., Woods, D., \& Ezekiel, E. J. (2013). The MOOC Phenomenon: Who Takes Massive Open Online Courses and Why? Open Education Europa. https://doi.org/10.2139/ssrn.2350964

Cole, A. W., \& Timmerman, C. E. (2015). What do current college students think about MOOCs? MERLOT Journal of Online Learning and Teaching, 11(2), 188-201.

Corbeil, J. R., Khan, B. H., \& Corbein, M. E. (2018). MOOCs revisited: Still transformative or passing fad? Asian Journal of University Education, 14(2), 1-12.

Daly, J. A., \& Miller, M. D. (1975). The empirical development of an instrument to measure writing apprehension. Research in Teaching of English, 9, 242-249. https://doi.org/10.1037/t73755-000

De Corte E., Engwall, L., \& Teichler, U. (2016). The hype of MOOCs. In E. De Corte, L. Engwall, \& U. Teichler, (Eds.), From books to MOOCs? Emerging models of learning and teaching in higher education (xv-xxv). London, England: Portland Press Wenner-Gren International Series.

Dey, I. (1993). Qualitative data analysis: A user-friendly guide. London, England: Routledge.

Feniger, Y., \& Ayalon, H. (2015). English as a gatekeeper: Inequality between Jews and Arabs in access to higher education in Israel. International Journal of Educational Research, 76, 104-111. https://doi.org/10.1016/j.ijer.2015.04.003

Fioriksdottir, F. (2017). The impact of different modalities on student retention and overall engagement patterns in open online courses. Computer Assisted Language Learning, 31(1-2), 53-71. https://doi.org/10.1080/09588221.2017.1381129

Flowerdew, J., \& Peacock, M. (2001). Issues in EAP: Preliminary perspectives. In J. Flowerdew \& M. Peacock (Eds.), Research perspectives on English for academic purposes (pp. 8-24). Cambridge, UK: Cambridge University Press. https://doi.org/10.1017/CBO9781139524766.004

Gameel, B. G., \& Wilkins, K. G. (2019). When it comes to MOOCs, where you are from makes a difference. Computers \& Education, 136(1), 49-60. https://doi.org/10.1016/j.compedu.2019.02.014

Garrison, R., \& Cleveland-Innes, M. (2005). Facilitating Cognitive Presence in Online Learning: Interaction Is Not Enough. The American Journal of Distance Education, 19(3), 133-148. https://doi.org/10.1207/s15389286ajde1903_2

Guri-Rosenblit, S. (2006). Eight paradoxes in the implementation process of e-learning in higher education. Distances et Savoirs, 4(2), 155-179. https://doi.org/10.3166/ds.4.155-179

Hew, K. F., \& Cheung, W. S. (2014). Students' and instructors' use of massive open online courses (MOOCs): Motivations and challenges. Educational Research Review, 12, 45-58. https://doi.org/10.1016/j.edurev.2014.05.001

Kebritchi, M., Lipschuetz, A. \& Santiague, L. (2017). Issues and Challenges for Teaching Successful Online Courses in Higher Education: A Literature Review. Journal of Educational Technology Systems, 46(1), 4-29. https://doi.org/10.1177/0047239516661713

Kelly, M. (2013). Issues for language policy in higher education. Sustainable Multilingualism, 2, 12-22. https://doi.org/10.7220/2335-2027.2.2 
Knesset, The Centre of Research and Information (2019). Teachers in the education system in Israel. Jerusalem, Israel.

Liyanagunawardena, T. R. (2015). Massive Open Online Courses. Humanities, 4, 35-41. https://doi.org/10.3390/h4010035

Mehran, P., Alizadeh, M., Koguchi, I., \& Tekmura, H. (2017). Are Japanese digital natives ready for learning English online? A preliminary case study at Osaka University. International Journal of Education Technology in Higher Education in Higher Education, 14(8), 1-17. https://doi.org/10.1186/s41239-017-0047-0

Online Course Report. (2016). Retrieved from https://www.onlinecoursereport.com/state-of-the-mooc-2016-a-year-of-massive-landscape-change-for-massiveopen-online-courses/

Prensky, M. (2012). Digital natives to digital wisdom: Hopeful essays for 21 st century education. Thousand Oaks, CA: Corwin Press. https://doi.org/10.4135/9781483387765

Ryan, G. W., \& Bernard, R. H. (2000). Data management and analysis methods. In Denzin, N. K., \& Lincoln, Y. S. (Eds.), Handbook of qualitative research (2nd ed., pp. 769-802), Thousand Oaks, CA: Sage.

Wallace, R. M. (2003). Online learning in higher education: A review of research on interactions among teachers and students. Education Communication and Information, 2, 241-280. https://doi.org/10.1080/14636310303143

Wang, X., Hall, A., \& Wang, Q. (2018). Investigating the implementation of accredited massive online open courses (MOOCs) in higher education: The boon and the bane. Australasian Journal of Educational Technology, 35(3), 1-14. https://doi.org/10.14742/ajet.3896

Yao, C. (2019). A case study of Chinese adult learners' English acquisition in a blended learning environment. Australian Journal of Adult Learning, 59(1), 115-135.

\section{Copyrights}

Copyright for this article is retained by the author(s), with first publication rights granted to the journal.

This is an open-access article distributed under the terms and conditions of the Creative Commons Attribution license (http://creativecommons.org/licenses/by/4.0/). 